\title{
Synthesis and Characterization of Bi-Functional Poly (Acrylic Acid-Co-2-hydroxyethylmethacrylate) Coated Iron Oxide Magnetic Composite Particles
}

\author{
Tania Tofaz ${ }^{1}$, Dhananjoy Chandra Mahanto ${ }^{1}$, Shamima Akhter ${ }^{1}$, Md. Mahbubor Rahman², \\ M. Abdul Latif ${ }^{1, *}$ \\ ${ }^{1}$ Department of Chemistry, Begum Rokeya University, Rangpur, Bangladesh \\ ${ }^{2}$ Department of Chemistry, University of Rajshahi, Rajshahi, Bangladesh
}

Email address:

latif503@brur.ac.bd (M. A. Latif)

${ }^{*}$ Corresponding author

\section{To cite this article:}

Tania Tofaz, Dhananjoy Chandra Mahanto, Shamima Akhter, Md. Mahbubor Rahman, M. Abdul Latif. Synthesis and Characterization of BiFunctional Poly (Acrylic Acid-Co-2-hydroxyethylmethacrylate) Coated Iron Oxide Magnetic Composite Particles. American Journal of Polymer Science and Technology. Vol. 5, No. 1, 2019, pp. 1-8. doi: 10.11648/j.ajpst.20190501.11

Received: January 7, 2019; Accepted: February 11, 2019; Published: March 5, 2019

\begin{abstract}
This paper covers the targetable magnetic iron oxide core and biodegradable, cost-effective, eco-friendly polymer shell considering their versatile and extensive use in various fields. In this work, poly (acrylic acid-co-2hydroxyethylmethacrylate) [P (AA-co-HEMA)] magnetic composite polymer particles were synthesized by the method of twostage solution polymerization in aqueous media. At first synthesis, the $\mathrm{Fe}_{3} \mathrm{O}_{4}$ particles by a traditional co-precipitation method and in the second stage occurs the formation of the polymer using acrylic acid (AA) as monomer and 2-hydroxyethyl methacrylate (HEMA) as co-monomer. Finally, the synthesized iron oxide particles encapsulated by a polymer to modify the surface of composite particles. The modified composite particles were then characterized by Scanning Electron Microscopy (SEM), Fourier Transform Infrared Spectroscopy (FTIR), X-ray Diffractometry (XRD), Dynamic Light Scattering (DLS), Thermo Gravimetric Analysis (TGA) and Vibrating Sample Magnetometry (VSM). The existence of carboxyl (-COOH) \& hydroxyl $(-\mathrm{OH})$ groups in the composite particles was confirmed by FTIR. XRD indicated the crystalline cubic spinel structure of magnetic composite particles. VSM results showed that the synthesized coated composite particles were paramagnetic in nature magnetic saturation is obtained $72.72 \mathrm{emu} / \mathrm{g}$ and $97.9 \mathrm{emu} / \mathrm{g}$ for bare $\mathrm{Fe}_{3} \mathrm{O}_{4}$ and coated magnetic composite particles respectively.
\end{abstract}

Keywords: Radical Copolymerization, AA, HEMA, MNPs

\section{Introduction}

Polymer microspheres are attracted much attention by the researchers because of their wide applications in biotechnology, paints and ink formulation, textile industry, electronics, and chromatography. These applications are attributed to their easy preparation $[1,2]$, clean and large specific surface area.

Various approaches to the synthesis of magnetic polymer particles have been investigated [3-8]. These include the coprecipitation of ferrous and ferric salts under alkaline conditions in presence of either polymers or surfactants, cross-linking of functional polymers in an emulsifierstabilized magnetic nanoparticle dispersion and layer-bylayer self-assembly of alternating layers of polyelectrolyte and magnetic nano-particles onto colloidal templates [9$11]$.

The fabrication of hybrid inorganic/organic polymer composites offers advantages especially when those applications depend on mechanical and surface properties. These inorganic-organic hybrid polymer particles find wide application potentials in catalysis, electrical, optical and electronic or photonic devices, biomaterials, flameretardant and coatings [12-20]. There is an increasing interest in the synthesis of nano-sized metal oxides 
because of their large surface area unusual adsorptive properties, surface defects, fast diffusivities and quantum size effects which are different from those of bulk materials [21-25]. Metal (oxide) composite particles $1 \mu$ to several microns have received widespread interest recently because of their envisioned applications in electronics, optics, and magnetic storage devices. Among the various oxide materials, $\mathrm{Fe}_{3} \mathrm{O}_{4}$ is a very important magnetic material extensively used in catalysis, battery cathodes, gas sensors, electronic films, and magnetic materials [2635]. These mechanical and physical properties, as well as application potentials, can be further improved by reducing the size and size distribution in the nano-range [36]. Despite the wide application potential of hybrid $\mathrm{Fe}_{3} \mathrm{O}_{4}$ composite polymer particles in different fields, only a few reports are available on the designing of such polymer particles.

\section{Materials and Methods}

\subsection{Materials}

Acrylic acid (AA) and 2-Hydroxy Ethyl Methacrylate (HEMA) purchased from Fluka, Germany, were distilled under reduced pressure to remove inhibitors and preserved in the refrigerator until use. Here acrylic acid was used as a monomer and a self-polymeric stabilizer due to having its exceptional behavior to iron oxide magnetic particles. HEMA was used as a co-monomer giving stability to the composite particles. Potassium persulfate (KPS) purchased from LOBA, India, was preserved in the refrigerator before use. KPS was used as a free radical initiator to the polymerization reaction. $25 \% \mathrm{NH}_{4} \mathrm{OH}$ purchased from Merck, Germany and other chemicals used were of analytical grade. Deionized water was distilled using a glass (Pyrex) distillation apparatus.

\subsection{Preparation of Iron Oxide Magnetic $\left(\mathrm{Fe}_{3} \mathrm{O}_{4}\right)$ Particles}

As shown in Figure 1, iron oxide magnetic $\left(\mathrm{Fe}_{3} \mathrm{O}_{4}\right)$ particles were prepared by co-precipitation method using $\mathrm{FeCl}_{3}(0.9661 \mathrm{~g})$ and $\mathrm{FeSO}_{4} .7 \mathrm{H}_{2} \mathrm{O}(0.834 \mathrm{~g})$ as $2: 1$ stoichiometric molar ratio in presence of $25 \% \mathrm{NH}_{4} \mathrm{OH}(14$ $\left.\mathrm{mL} \mathrm{p}{ }^{\mathrm{H}}>10\right) . \mathrm{FeCl}_{3}$ and $\mathrm{FeSO}_{4} \cdot 7 \mathrm{H}_{2} \mathrm{O}$ salts were taken into two beakers each of which were $50 \mathrm{ml}$ and then added $88 \mathrm{~mL}$ of $\mathrm{DD}-\mathrm{H}_{2} \mathrm{O}$ as solvent. Then passed $\mathrm{N}_{2}$ gas to remove oxygen about 10 minutes. After that the two solution mixed and further passed $\mathrm{N}_{2}$ gas for inert medium. Then it was taken in a $500 \mathrm{ml}$ beaker which was already set at paraffin oil bath at $85^{\circ} \mathrm{C}$ and stirred at 900 rpm for 2 hours.

$$
\mathrm{FeCl}_{3}(\mathrm{~s})+\mathrm{FeSO}_{4} \cdot 7 \mathrm{H}_{2} \mathrm{O}(\mathrm{s}) \stackrel{25 \% \mathrm{NH}_{4} \mathrm{OH}}{\stackrel{\mathrm{N}_{2}(\mathrm{~g}), 900 \mathrm{rpm}, 2 \mathrm{hrs} .}{\longrightarrow}} \quad \begin{gathered}
\mathrm{Fe}_{3} \mathrm{O}_{4} \\
\begin{array}{c}
\text { Iron Oxide } \\
\text { Magnetic particle }
\end{array}
\end{gathered}
$$

Table 1. The preparation of iron oxide magnetic nanoparticles.

\begin{tabular}{ll}
\hline Ingredients & Amount(g) \\
\hline $\mathrm{FeCl}_{3}$ & 0.9661 \\
$\mathrm{FeSO}_{4} \cdot 7 \mathrm{H}_{2} \mathrm{O}$ & 0.834 \\
$25 \% \mathrm{NH}_{4} \mathrm{OH}$ & $14(\mathrm{ml}) \mathrm{pH}>10$ \\
$\mathrm{DD}-\mathrm{H}_{2} \mathrm{O}$ & 88 \\
\hline
\end{tabular}

Reaction conditions: $85^{\circ} \mathrm{C}, 900 \mathrm{rpm}, 2$ hours, $\mathrm{N}_{2}$ atmosphere.

\subsection{Preparation of Poly (AA-co-HEMA)}

Poly [AA-HEMA] was prepared by addition polymerization from acrylic acid with 2-Hydroxy Ethyl Methacrylate using potassium persulphate (KPS) as an initiator shown in Figure 2. Here acrylic acid (AA) was used as a promising and efficient stabilizer. 0.448 gm acrylic acid and 0.111 gm HEMA [ $4: 1$ weight content] were taken in a three necked round bottom glass reactor immersed in a thermo stated water bath as a monomer \& co-monomer respectively. Then $0.016 \mathrm{gm}(2 \%$ weight content of AAHEMA) KPS was mixed as initiator. Then the mixture was stirred at $70^{\circ} \mathrm{C}$ in presence $\mathrm{N}_{2}$ atmosphere for 5 hours under mild stirring (about 120 revolutions per minutes). Polymerization conditions were shown in Table 2.

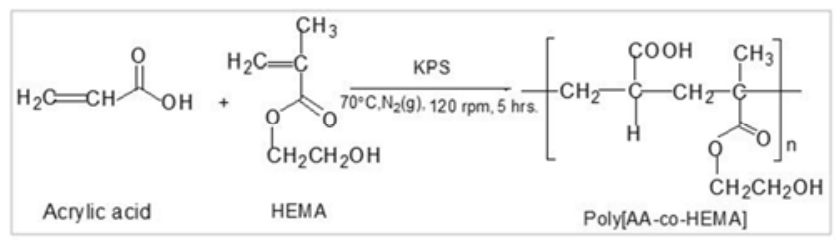

Figure 2. The reaction schemes for the synthesis of copolymer, poly (AAHEMA) by free radical polymerization.

Table 2. The synthesis of copolymer, poly (AA-HEMA) by free radical polymerization.

\begin{tabular}{ll}
\hline Ingredients & Amount (gm) \\
\hline AA & 0.448 \\
$\mathrm{HEMA}$ & 0.111 \\
$\mathrm{KPS}$ & 0.016 \\
$\mathrm{DD}-\mathrm{H}_{2} \mathrm{O}$ & 49.216 \\
\hline
\end{tabular}

Reaction conditions: $70^{\circ} \mathrm{C}, 120 \mathrm{rpm}, 5$ hours, $\mathrm{N}_{2}$ atmosphere radical polymerization.

\subsection{Preparation of Polymer-Coated Iron Oxide $\left(\mathrm{Fe}_{3} \mathrm{O}_{4}\right)$ Magnetic Composite Particles}

After preparation of iron oxide magnetic $\left(\mathrm{Fe}_{3} \mathrm{O}_{4}\right)$ particles, $50 \%$ of these were separated for bare $\mathrm{Fe}_{3} \mathrm{O}_{4}$ and rest of them were added to a three-necked round bottom flask containing copolymer [AA-co-HEMA] immediately.

The solution was highly dispersed and turned to brownish from black. Then the mixture was stirred about 12 hours at $70^{\circ} \mathrm{C}$ in a thermostatic water bath. After 12 hours the polymer coated composite particles were washed from the dispersed solution by DD- $\mathrm{H}_{2} \mathrm{O}$ using a magnet. This procedure was carried out about several times and finally, the particles were dried in an oven at about $60^{\circ} \mathrm{C}$ temperature. 


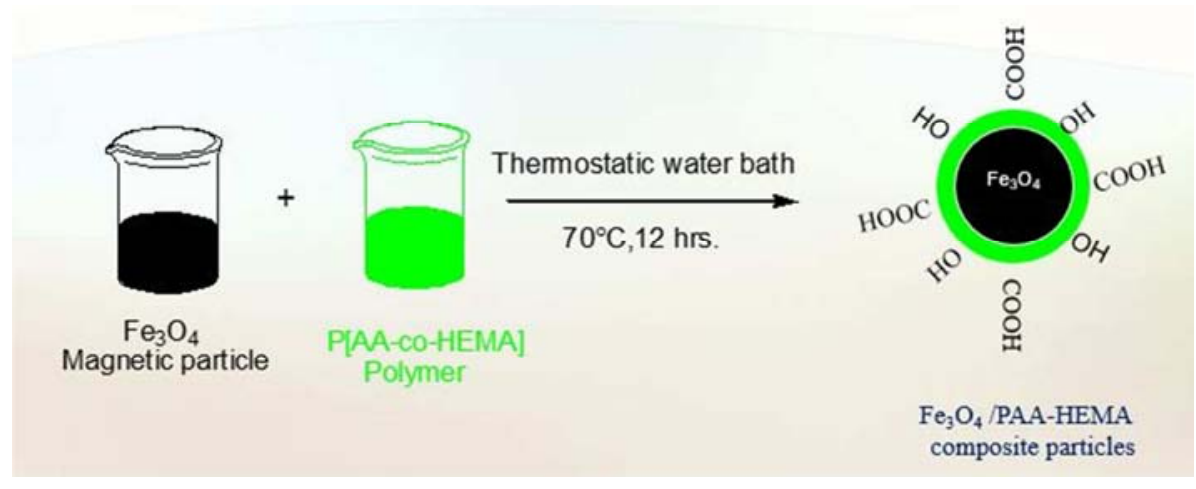

Figure 3. Surface modification of iron oxide $\left(\mathrm{Fe}_{3} \mathrm{O}_{4}\right)$ magnetic nano-particles with poly (AA-HEMA).

\subsection{Characterization}

The morphological images i.e., size and shape of the bare $\mathrm{Fe}_{3} \mathrm{O}_{4}$ particles were taken by SEM FEI, Quanta Inspect, made in the Czech Republic at $15 \mathrm{kV}$ and $\mathrm{Fe}_{3} \mathrm{O}_{4} / \mathrm{PAA}$-HEMA composite particles were obtained by scanning electron microscopy (SEM) on a JEOL, model JSM 6490L, USA, operating at 20kV. The interaction (molecular structure) between the magnetic composite particles and the polymer i.e. presence of functional groups in the synthesized polymer coated magnetic composite particles were investigated by Fourier Transform Infrared spectroscopy (FTIR). The equipment used for the analysis of FTIR spectroscopy was carried out at the range of $10^{\circ} \mathrm{C}$ to $70^{\circ} \mathrm{C}$. Thermal behavior of bare $\mathrm{Fe}_{3} \mathrm{O}_{4}$ and $\mathrm{Fe}_{3} \mathrm{O}_{4} / \mathrm{PAA}$-HEMA magnetic composite particles were recorded by TGA-50, Shimadzu, Japan. In this technique, samples were analyzed $\%$ weight vs. temperature from room temperature to $600^{\circ} \mathrm{C}$ at a heating rate of $10^{\circ} \mathrm{C} / \mathrm{min}$ under $\mathrm{N}_{2}$ atmosphere. An X-ray diffract to meter of Rigaku brand, model Ultima IV, USA, operating at $40 \mathrm{kV}, 17.5 \mathrm{~mA}, 200 \mathrm{~V}$, equipped with copper tube $(\lambda=0.154 \mathrm{~nm})$ was used for the analysis of crystal structure of prepared composite particles. The hydrodynamic diameter of the polymer particles was measured by (DLS) NICOMP 380, USA. The magnetic property of $\mathrm{Fe}_{3} \mathrm{O}_{4}$ and $\mathrm{Fe}_{3} \mathrm{O}_{4} / \mathrm{PAA}$-HEMA composite particles were characterized by vibrating sample magnetometer namely microsense VSM.

\subsection{Thermogravimetric Analysis (TGA) of $\mathrm{Fe}_{3} \mathrm{O}_{4}$ and $\mathrm{Fe}_{3} \mathrm{O}_{4}$ Coated with Poly (AA-co- HEMA) Particles}

Thermal properties of the dried $\mathrm{Fe}_{3} \mathrm{O}_{4}$ and $\mathrm{Fe}_{3} \mathrm{O}_{4}$ coated with Poly [AA- co- HEMA] powder were measured by heating samples under flowing nitrogen atmosphere from $25^{\circ} \mathrm{C}$ to $600^{\circ} \mathrm{C}$ at a heating rate of $20^{\circ} \mathrm{C} / \mathrm{min}$ and the weight loss was recorded.

\section{Results and Discussion}

Figure 4 shows the SEM photographs of bare $\mathrm{Fe}_{3} \mathrm{O}_{4}$ and $\mathrm{Fe}_{3} \mathrm{O}_{4}$,PAA-HEMA magnetite composite particles. From the
SEM photographs, it was found that microspheres of $\mathrm{Fe}_{3} \mathrm{O}_{4} /$ PAA-HEMA composites were spherical in shape, highly dispersed in solution but particles were agglomerated [Figure 4 (c) and (d)]. Therefore, the actual particle size was not confirmed by this test. On the other hand, due to lack of proper sampling size of bare $\mathrm{Fe}_{3} \mathrm{O}_{4}$ particles could not be measured. However, the particles supported good crystal surface.
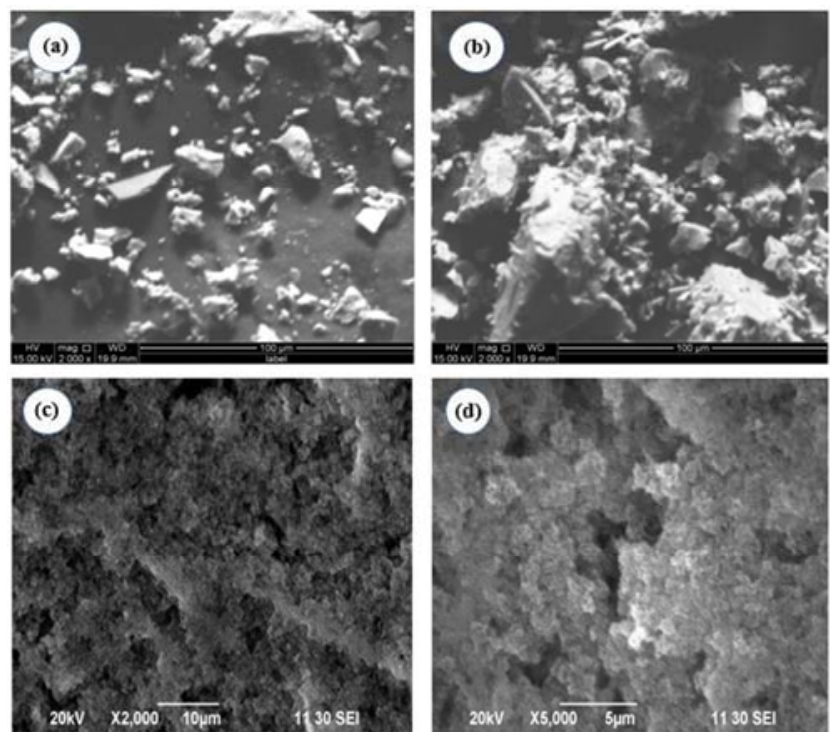

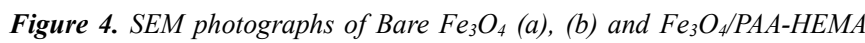
composite particles (c), (d).

Figure 5 represents the characteristics vibrational spectroscopy of bare $\mathrm{Fe}_{3} \mathrm{O}_{4}$ composite particles and polyacrylic acid co 2-hydroxyl ethylmethacrylate coated iron oxide composite particles, respectively. The fingerprint of $\mathrm{Fe}_{3} \mathrm{O}_{4}$ occurs mainly at $480.28 \mathrm{~cm}^{-1}$ and $650.01 \mathrm{~cm}^{-1}$ where two medium sharp peaks correspond to the presence of Fe-OFe stretching bond in $\mathrm{Fe}_{3} \mathrm{O}_{4}$ magnetic particles [37]. Broad absorption above $3000 \mathrm{~cm}^{-1}$ typically stands for the stretching vibration of $\mathrm{O}-\mathrm{H}$ bonds in hydroxyl group of a carboxylic acid which corresponds at $3477.66 \mathrm{~cm}^{-1}$ [38]. 


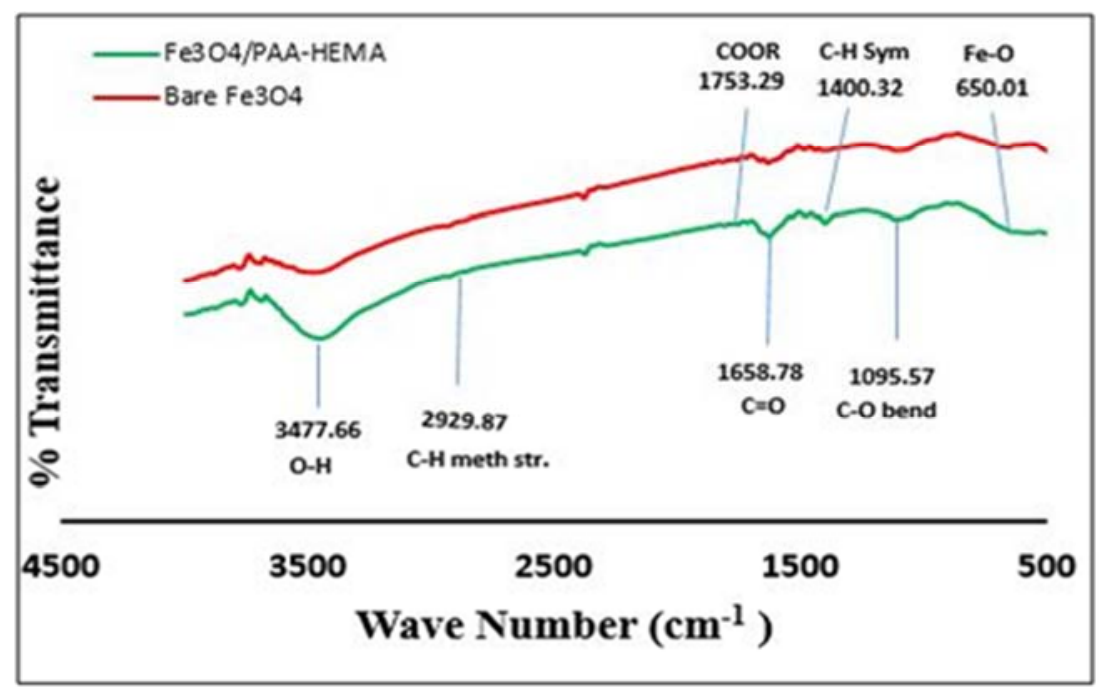

Figure 5. FTIR analysis of bare $\mathrm{Fe}_{3} \mathrm{O}_{4}$ and $\mathrm{Fe}_{3} \mathrm{O}_{4} / \mathrm{PAA}$-HEMA magnetic composite particles.

The two doublets at $1625.99 \mathrm{~cm}^{-1}$ and $1658.78 \mathrm{~cm}^{-1}$ represent the presence of carbonyl $(\mathrm{C}=\mathrm{O})$ group. Moreover, absorption at $1753.29 \mathrm{~cm}^{-1}$ and $1095.57 \mathrm{~cm}^{-1}$ correspond to stretching vibration of ester (-COOR) group and C-O bond [39], respectively. The absorption peak just below the 3000 $\mathrm{cm}^{-1}$ i.e., at $2929.87 \mathrm{~cm}^{-1}$ corresponds to stretching of the methyl group $\left(-\mathrm{CH}_{3}\right)$ [40] while two doublets at $1400.32 \mathrm{~cm}^{-1}$ and $1479.40 \mathrm{~cm}^{-1}$ signify the symmetric and asymmetric vibration of $(\mathrm{C}-\mathrm{H})$ bond in the resultant composite particles. All the above information indicates the polymer coated iron oxide composite particles [41].

The XRD pattern of $\mathrm{Fe}_{3} \mathrm{O}_{4}$ composite particles were prepared at room temperature is shown in Figure 6. The modified $\mathrm{Fe}_{3} \mathrm{O}_{4}$ particles exhibited main peaks at 2 theta (deg) of $30.5,35.8,43.3,53.9, \quad 57.4,62.8,74.5$, corresponding to the (220), (311), (400), (422), (511), (440), (533) reflection planes of the face-centered cubic crystal $\mathrm{Fe}_{3} \mathrm{O}_{4}$ [42]. The XRD data clearly confirmed the crystalline phase of magnetite $\left(\mathrm{Fe}_{3} \mathrm{O}_{4}\right)$ to be very close to the JCPDS No. 89-4319. For the prepared $\mathrm{Fe}_{3} \mathrm{O}_{4}$, the most intensive lines (311) and (440) were observed the diffraction peak indicated at $2 \theta=35.8$ and 62.8 . The XRD pattern showed the prepared composite particles were in a cubic structure of $\mathrm{Fe}_{3} \mathrm{O}_{4}$. It could be seen that the sites and intensity of the diffraction peaks were consistent with the standard pattern for JCPDS Card No. 89-4319. The sample showed very broad peaks, indicating the ultra-fine nature and small crystalline size of the particles. The XRD pattern of the modified $\mathrm{Fe}_{3} \mathrm{O}_{4} \mathrm{NPs}$, indicating that a portion of the $\mathrm{Fe}_{3} \mathrm{O}_{4}$ NPs was successfully encapsulated by a copolymer (AA-co-HEMA).

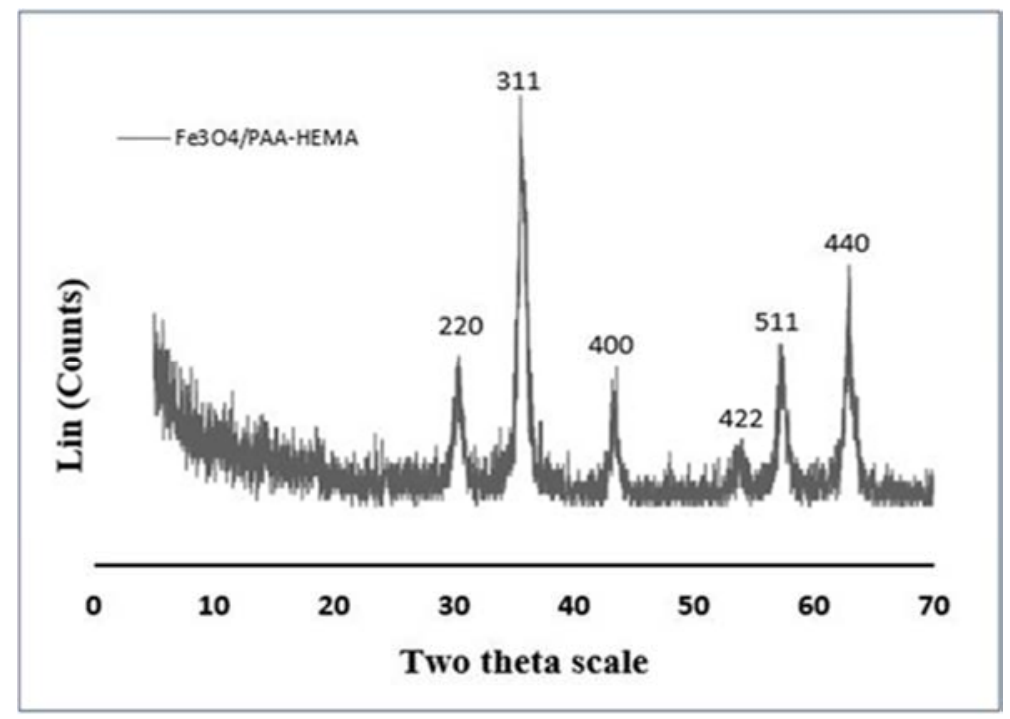

Figure 6. The XRD pattern of $\mathrm{Fe}_{3} \mathrm{O}_{4}$ composite particles at room temperature.

The TGA curve of $\mathrm{Fe}_{3} \mathrm{O}_{4}$ MNPs coated with Poly (AA- coHEMA) is shown in Figure 7. There were five decomposition points in the curve which indicated the four mass losses of coated iron oxide magnetic nanoparticles with respect to time. The observation was carried out at ambient temperature $29.03^{\circ} \mathrm{C}$. The first decomposition point was at about $97.07^{\circ} \mathrm{C}$, which was around the boiling or decomposition point of HEMA, and the percentage of mass loss was about 
$2.15 \%$, which possibly due to the removal of free polyacrylic acid co- HEMA on the surface of $\mathrm{Fe}_{3} \mathrm{O}_{4}$ MNPs. The second point was at $270.70^{\circ} \mathrm{C}$ and the percentage of mass loss was about $4.18 \%$, which confirmed that the percentage of mass loss was increased with increasing time and temperature. The third point was at $351.57^{\circ} \mathrm{C}$, and the percentage of mass loss was about $10.02 \%$ which was attributed to the phase transition from $\mathrm{Fe}_{3} \mathrm{O}_{4}$ to $\mathrm{FeO}$. The fourth point at $458.04^{\circ} \mathrm{C}$, related to a mass loss of $11.21 \%$, possibly because of deoxidation of $\mathrm{FeO}$ since the TGA analysis was achieved under the $\mathrm{N}_{2}$ atmosphere [43]. The fifth decomposition point is about at $599.52^{\circ} \mathrm{C}$ and the percentage of mass loss was found as $11.40 \%$. Consequently, from Figure 7 the coating content of modified iron oxide nanoparticles was estimated to be about $11.40 \%$.

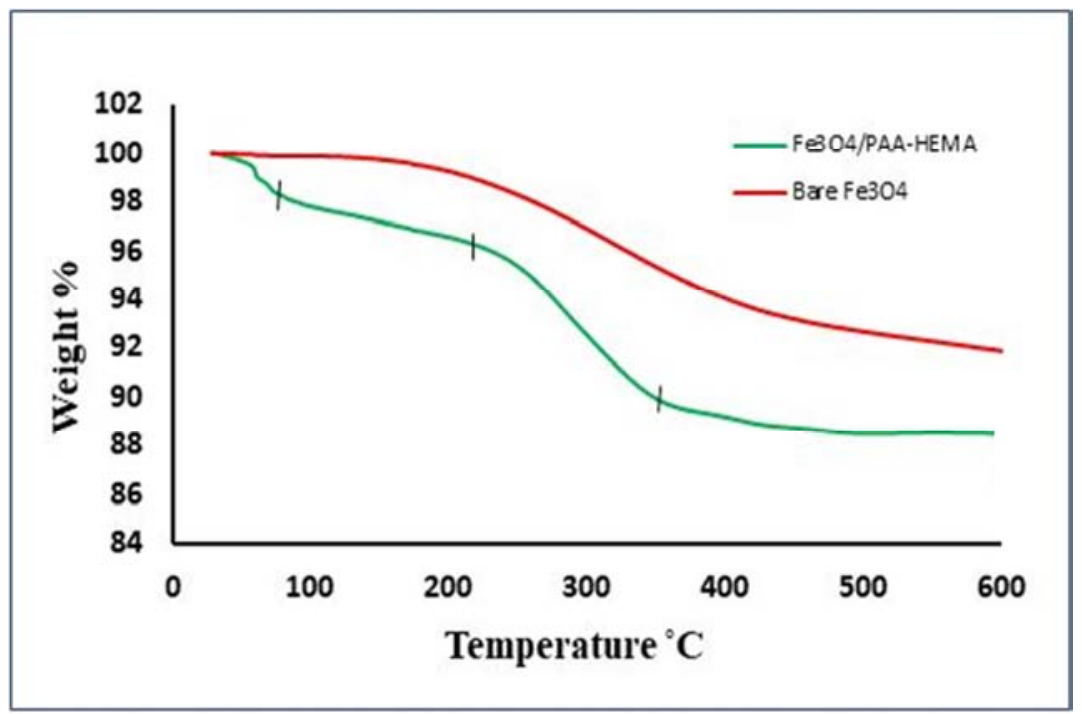

Figure 7. The TGA curve of $\mathrm{Fe}_{3} \mathrm{O}_{4} \mathrm{MNPS}$ coated with Poly [AA- co- HEMA].

Figure 8 shows the measurement of the hydrodynamic diameter of washed $\mathrm{Fe}_{3} \mathrm{O}_{4}$ /PAA-HEMA composite polymer particles with $\mathrm{p}^{\mathrm{H}} 8$ at room temperature. The obtained mean diameter was $1426.8 \mathrm{~nm}$ where the coefficient of variation and the standard deviation was 0.689 and $983.042 \mathrm{~nm}$ respectively.

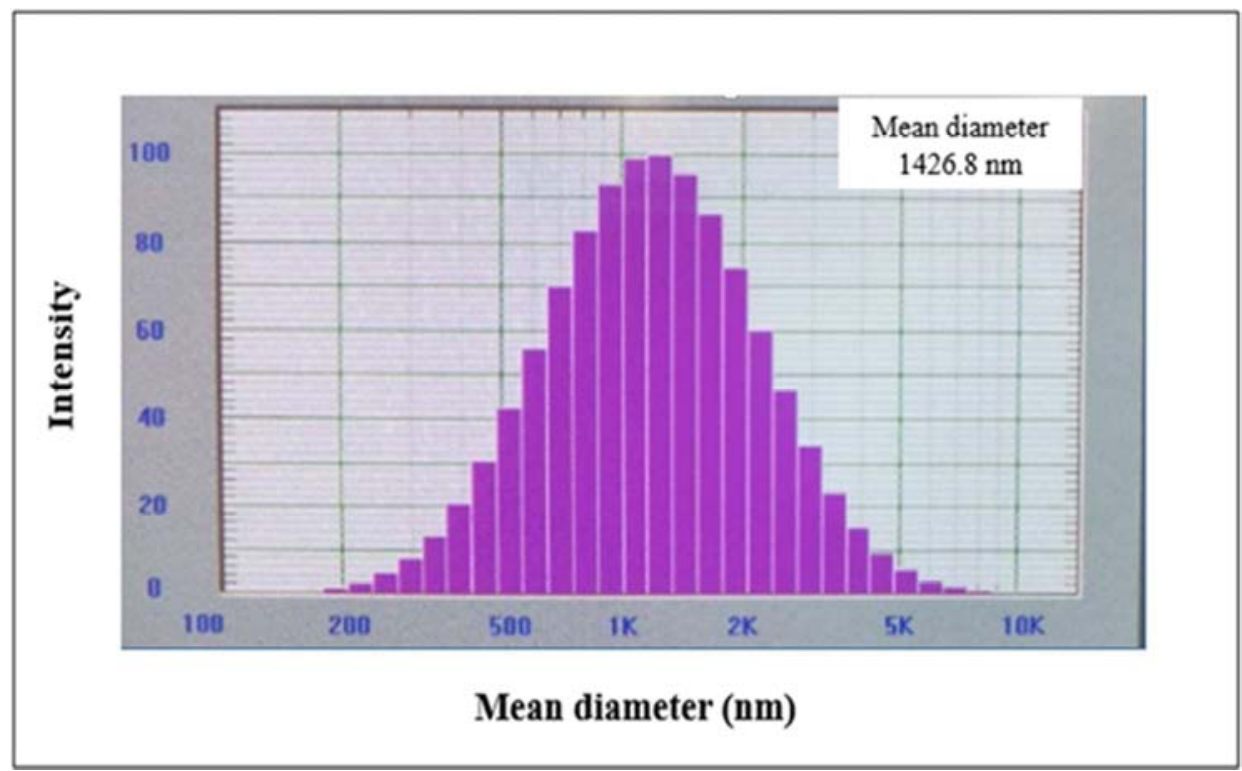

Figure 8. The size distribution of $\mathrm{Fe}_{3} \mathrm{O}_{4} / P A A-H E M A$ composite polymer particles obtained from DLS.

Figure 9 shows the presence of magnetic property in the composite particles coated with P(AA-co-HEMA) was characterized by the application of an external magnetic field [44]. The magnetic behavior of the iron oxide composite particles and the same composite particles coated with the polymer could be observed from the measurements of the magnetization at room temperature. According to the magnetization curves, there was no hysteresis loop in the magnetization for both of samples, suggesting the magnetic particles possess typical super paramagnetic behavior. The saturation magnetization of the uncoated particles was 72.72 $\mathrm{emu} / \mathrm{g}$ and the corresponding value, for the composite 
particles coated with the polymer, was $97.9 \mathrm{emu} / \mathrm{g}$ [45]. The saturation magnetization values of $\mathrm{P}$ (AA-co-HEMA) coated $\mathrm{Fe}_{3} \mathrm{O}_{4}$ was higher than the value for the pure magnetite particles, therefore the saturation magnetization was increased after coating of acrylic acid and HEMA onto the surface of $\mathrm{Fe}_{3} \mathrm{O}_{4}$ magnetic particles. This could be explained by the size and the broader distribution of the coated the composite particles, as well as, the fact that the composite particles uncoated when exposed to the environment, might undergo oxidation and consequently losing magnetism. The uncoated composite particles showed a smaller diameter and, consequently, smaller protection against oxidation [46].

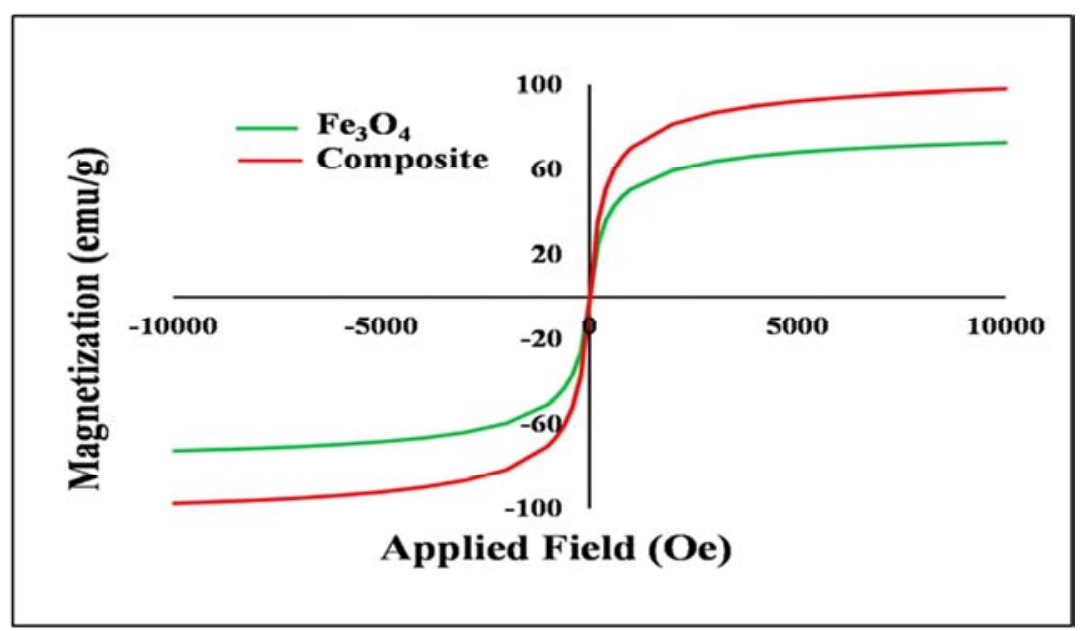

Figure 9. The VSM data curve for bare $\mathrm{Fe}_{3} \mathrm{O}_{4}$ and PAA-HEMA coated iron oxide nanoparticles.

\section{Conclusion}

Synthesis and characterization of bi-functional PAA-HEMA coated $\mathrm{Fe}_{3} \mathrm{O}_{4}$ magnetic composite particles were prepared with the aim of enhancing the surface modification of $\mathrm{Fe}_{3} \mathrm{O}_{4}$. Magnetite composite particles were prepared by two-step preparation process. In the first step, magnetite particles were prepared by co-precipitation of $\mathrm{Fe}^{2+}$ and $\mathrm{Fe}^{3+}$ salts in presence of $25 \%$ ammonium hydroxide. In the second step, the produced magnetite particles were coated with a bi-functional polymer polyacrylic acid (AA) and 2-hydroxyethyl-methacrylate (HEMA) prepared by solution polymerization. The resulting samples of composite particles were analyzed utilizing SEM, FTIR, TGA, XRD, DLS, and VSM. SEM analysis showed that microspheres of $\mathrm{Fe}_{3} \mathrm{O}_{4}$ / PAA-HEMA composite were spherical in shape, highly dispersed in solution but particles were agglomerated. Therefore, the actual particle size was not confirmed by this test. Besides this finding, the average particle size of hydrodynamic diameter was confirmed by DLS analysis with the gradual ultra-sonication method. According to the FTIR results, microsphere containing different amount of AA and HEMA in copolymer structure having carboxylic $(-\mathrm{COOH})$ and hydroxyl $(-\mathrm{OH})$ functional groups on the side chain of the copolymer was confirmed. The presence of $\mathrm{Fe}_{3} \mathrm{O}_{4}$ in the microsphere was also proved by FT-IR spectroscopy analysis and TGA analysis. From the TGA results the thermal behavior of prepared composite particles were confirmed by the degradation curve with respect to temperature vs. $\%$ of weight. It was also supported that the absorbed water molecules and bonding in the polymer were degraded as temperature increased to $600^{\circ} \mathrm{C}$. The data obtained by particle size analysis indicated that the hydrodynamic mean diameter of microsphere was $1426.8 \mathrm{~nm}$ i.e. $1.42 \mu \mathrm{m}$ approximately using DLS. VSM analysis of the prepared $\mathrm{Fe}_{3} \mathrm{O}_{4} /$ PAA-HEMA composite particles showed abnormal behavior as there was noticed that the saturation magnetization increased after coating copolymer PAA-HEMA on the surface of bare $\mathrm{Fe}_{3} \mathrm{O}_{4}$ core. This is an interesting finding of this research. Moreover, in this work, no stabilizer was used separately as conventional emulsion, dispersion or solution polymerization method used. Due to special properties, AA supporting with HEMA was found as an efficient stabilizer in this work. Our findings may also open the possible way to prepare microsphere with $\mathrm{Fe}_{3} \mathrm{O}_{4}$ in the core by varying the amount of AA and HEMA. However, in each case, an increase in HEMA content in the composite polymer particles decreased the hydrophobic interaction between the surface of particles and biomolecules. Therefore, it can be concluded that the ratio of HEMA should be as low as possible to obtain high ratios of encapsulation. This study indicated that magnetically modified $\mathrm{Fe}_{3} \mathrm{O}_{4} / \mathrm{PAA}-\mathrm{HEMA}$ composite particles were successfully prepared and these particles may find applications in biomedical field.

\section{Acknowledgements}

This work was supported by the financial grant of National Science \& Technology (NST), Ministry of Science, Government of the People's Republic of Bangladesh and cordial help of polymer colloidal laboratory of Chemistry department from Rajshahi University, Bangladesh.

\section{References}

[1] P. Volfova, V. Chrastova, L. Cernakova, J. Mrenica, J. Kozankova, Properties of polystyrene/poly(butyl acrylate) core/shell polymers modified with n-methylol acrylamide. Macromol. Symp., 2001, 170, 283-290. 
[2] S. E. Shim, Y. J. Cha, J. M. Byun, S. Choe, Size Control of Polystyrene Beads by Multistage Seeded Emulsion Polymerization. J. App. Polym. Sci., 1999, 71, 2259-2269.

[3] R. Tong, Y. Wang, G. Yang, A. Ma, K. Sun, H. Yang and J. Wang, Study of preparation and properties on polymermodified magnetite nanoparticles. S. Afr. J. Chem., 2015, 68, 99-104.

[4] Z. P. Xiao, K. M. Yang, H. Liang, J. Lu, Synthesis of Magnetic, Reactive, and Thermo responsive $\mathrm{Fe}_{3} \mathrm{O}_{4}$ Nanoparticles via Surface-Initiated RAFT Copolymerization of N-Isopropylacrylamide and Acrolein. Journal of Polymer Science, 2010, 48 (3), 542-550.

[5] H. Ahmad, M. M. Hossain, M. M. Rahman, and M. A. Jalil Miah, Monodispersed Carboxylated Composite Polymer Microspheres and Physical Immobilization of Biomolecules. Polymer journal, 2007, 39 (5), 428-434.

[6] J. Xu, and Z. Fan, Poly[ $N$-isopropylacrylamide-co-3(trimethoxysilyl)-propylmethacrylate] Coated Aqueous Dispersed Thermosensitive $\mathrm{Fe}_{3} \mathrm{O}_{4}$ Nanoparticles. J. Phys. Chem. C, 2009, 113, 10090-10096.

[7] M. Mahdavi et.al, Synthesis, Surface Modification and Characterisation of Biocompatible Magnetic Iron Oxide Nanoparticles for Biomedical Applications. Molecules, 2013, 18 (7), 7533-7548.

[8] M. Rapado, C. Peniche, Synthesis and characterization of $\mathrm{pH}$ and temperature responsive poly(2-hydroxyethyl methacrylate-co-acrylamide) hydrogels. Polimeros. Ciencia. E. Tecnologia., 2015, 25 (6), 547-555.

[9] H. Ahmad, M. A. Rahman, M. A. J. Miah, and K. Tauer, Magnetic and temperature-sensitive composite polymer particles and adsorption behavior of emulsifiers and trypsin, Macromolecular Research, 2008, 16, 637-643.

[10] L. Zhuang, Y. Zhao, H. Zhong, et al., Hydrophilic Magnetochromatic Nanoparticles with Controllable Sizes and Super-high Magnetization for Visualization of Magnetic Field Intensity. Scientific Reports, 2015, 5, 17063, 1-9.

[11] H. Ahmad, A. H. M. T. Islam, M. A. Hossain, M. A. J. Miah, K. Tauer, Emulsion Copolymerization of Hydrophobic and Hydrophilic Monomers: An Experimental Study With Styrene and 2-Hydroxyethyl Methacrylate. e-Polymers, 2006, Number 030 .

[12] Gowariker, V. R., Viswanathan, N. V. and Shreedhar, Polymer Science book, New Age International, 2005, New Delhi.

[13] J. W. Kim, J. W. Shim, J. H. Bae, S. H. Han, H. K. Kim, I. S. Chang, H. H. Kang, K. D. Suh, Titanium dioxide/poly (methyl methacrylate) composite microspheres prepared by in situ suspension polymerization and their ability to protect against UV rays. Colloid Polym. Sci., 2002, 280 (6), 584-588.

[14] N. Manoharan, M. T. Elsesser, D. J. Pine, Dense packing and symmetry in small clusters of microspheres. Science, 2003, $301,483-487$.

[15] Y. C. Chen, C. C. Tsai, Y. D. Lee, Preparation and properties of silylated PTFE/SiO $\mathrm{Si}_{2}$ organic-inorganic hybrids via sol-gel process. J. Polym. Sci. Part A: Polym. Chem., 2004, 42 (7), 1789-1807.

[16] M. A. Rahman, M. A. J. Miah, H. Minami, H. Ahmad, Preparation of magnetically doped multilayered functional silica particles via surface modification with organic polymer. Polym. Adv. Technol., 2013, 24 (2), 174-180.

[17] B. H. Shambharkar, S. S. Umare, Synthesis and characterization of polyaniline/ $\mathrm{NiO}$ nano composite. J. App. Polym. Sci., 2011, 122 (3), 1905-1912.

[18] I. Tissot, C. Novat, F. Lefebvre, E. Bourgeat-Lami, Hybrid latex particles coated with silica. Macromolecules, 2001, 34 (17), 5737-5739.

[19] C. L. Sun, L. C. Chen, M. C. Su, L. S. Hong, O. Chyan, C. Y. Hsu, K. H. Chen, T. F. Chang, L. Chang, Ultrafine platinum nanoparticles uniformly dispersed on arrayed $\mathrm{CN}_{x}$ nanotubes with high electrochemical activity. Chem. Mater, 2005, 17 (14), 3749-3754.

[20] S. Kawano, A. Sei, M. Kunitake, Sparsely distributed silica/PMAA composite particles prepared by static polymerization in aqueous silica dispersion. J. Colloid Interface Sci., 2010, 352 (2), 348-353.

[21] Y. Ichiyanagi, N. Wakabayashi, J. Yamazaki, S. Kimishima, E. Komatsu, H. Tajima, Magnetic properties of $\mathrm{NiO}$ nanoparticles. Phys. B Condensed Matt., 2003, 329, 862-863.

[22] K. Karthik, G. K. Selvan, M. Kanagaraj, S. Arumugam, N. V. Jaya, Particle size effect on the magnetic properties of $\mathrm{NiO}$ nanoparticles prepared by precipitation method. J. Alloy Comp., 2011, 509 (1), 181-184.

[23] J. H. Adair, T. Li, T. Kido, K. Havey, J. Moon, J. Mecholsky, A. Morrone, D. R. Talham, M. H. Ludwig, L. Wang, Recent developments in the preparation and properties of nanometersize spherical and platelet-shaped particles and composite particles. Mater. Sci. Eng. Rep., 1998, 23, 139-242.

[24] S. Gandhi, N. Nagalakshmi, I. Baskaran, V. Dhanalakshmi, M. R. G. Nair, R. Anbarasan, Synthesis and characterization of nano-sized $\mathrm{NiO}$ and its surface catalytic effect on poly(vinyl alcohol). J. App. Polym. Sci., 2010, 118 (3), 1666-1674.

[25] C.-B. Wang, G.-Y. Gau, S.-J. Gau, C.-W. Tang, J.-L. Bi, Preparation and characterization of nanosized nickel oxide. Catal. Letts., 2005, 101, 241-247.

[26] M. Yoshio, Y. Todorov, K. Yamato, H. Noguchi, J. Itoh, M. Okada, T. Mouri, Preparation of $\mathrm{Li}_{\mathrm{y}} \mathrm{Mn}_{\mathrm{x}} \mathrm{Ni}_{1}-\mathrm{XO}_{2}$ as a cathode for lithium-ion batteries. J. Power Sources, 1998, 74 (1), 4653.

[27] R. Alcantara, P. Lavela, J. L. Tirado, R. Stoyanova, E. Zhecheva, Changes in structure and cathode performance with composition and preparation temperature of lithium cobalt nickel oxide. J. Electrochem. Soc., 1998, 145 (3), 730-736.

[28] J. Park, E. Kang, S. U. Son, H. M. Park, M. K. Lee, J. Kim, K. W. Kim, H. J. Noh, J. H. Park, C. J. Bae, J.-G, Park, T. Hyeon, Monodispersed nanoparticles of $\mathrm{NiO}$ and $\mathrm{Ni}$ : synthesis, characterization, self-assembled super lattices, and catalytic application in the Suzuki Coupling Reaction. $A d v$. Mater., 2005, 17 (4), 429-434.

[29] X. Wang, L. Li, Y. G. Zhang, S. T. Wang, Z. D. Zhang, L. F. Fei, Y. T. Qian, High-yield synthesis of NiOnanoplatelets and their excellent electrochemical performance. Cryst. Growth. Des, 2006, 6 (9), 2163-2165.

[30] M. C. A. Fantini, F. F. Ferreira, A. Gorenstein, Theoretical and experimental results on $\mathrm{Au}-\mathrm{NiO}$ and $\mathrm{Au}-\mathrm{CoO}$ electrochromic composite films. Solid State Ionics, 2002, 152, 867-872. 
[31] J. Bandara, H. Weerasinghe, Solid state dye-sensitized solar cells with p-type $\mathrm{NiO}$ as the hole collector. Sol. Energy Mater. Sol. Cells, 2005, 85, 385-390.

[32] B. Huang, Q. C. Yu, H. M. Wang, G. Chen, K. A. Hu, Study of $\mathrm{LiFeO}_{2}$ coated $\mathrm{NiO}$ as cathodes for MCFC by electrochemical impedance spectroscopy. J. Power Sources, 2004, 137 (2), 163-174.

[33] I. Hotovy, V. Rehacek, P. Siciliano, S. Capone, L. Spiess, Sensing characteristics of $\mathrm{NiO}$ thin films as $\mathrm{NO}_{2}$ gas sensors. Thin Solid Film, 2002, 418 (1), 9-15.

[34] E. L. Mille, R. E. Rocheleau, Electrochemical behavior of reactively sputtered iron-doped nickel oxide. J. Electrochem. Soc., 1997, 144(9), 3072-3077.

[35] Z. Xu, M. Li, J. Y. Zhang, L. Chang, R. Q. Zhou, Z. T. Duan, Ultrafine NiO- $\mathrm{La}_{2} \mathrm{O}_{3}-\mathrm{Al}_{2} \mathrm{O}_{3}$ aerogel: a promising catalyst for $\mathrm{CH}_{4} / \mathrm{CO}_{2}$ reforming. Appl. Catal. A: General, 2001, 213 (1), 65-71.

[36] S. Deki, H. Yanagimoto, S. Hiraoka, K. Akamatsu, K. Gotoh, $\mathrm{NH}_{2}$-terminated poly(ethylene oxide) containing $\mathrm{NiO}$ particles: synthesis, characterization and structural considerations. Chem. Mater., 2003, 15 (26), 4916-4922.

[37] S. Pereira da Silva, D. Costa de Moraes, D. Samios, Iron Oxide Nanoparticles Coated with Polymer Derived from Epoxidized Oleic Acid and Cis-1,2-Cyclohexanedicarboxylic Anhydride: Synthesis and Characterization. J Material Sci Eng., 2016, 5 (3), 2-7.

[38] Yuen-Jian C, Juan T, Fei X, Jia-Bi Z, Nin G, et al. Oleic acid were chemisorbed onto the $\mathrm{Fe}_{3} \mathrm{O}_{4}$ nanoparticles as a carboxilate. Drug DevInd Pharm, 2010, 36, 1235-1244.

[39] A. Nicolau, R. M. Mariath, E. A. Martini, D. Samios, The polymerization products of epoxidized oleic acid and epoxidized methyl oleate with cis-1,2cyclohexanedicarboxylic anhydride and triethylamine as the initiator: Chemical structures, thermal and electrical properties. Mater Sci Eng C, 2010, 30, 951-962.

[40] M. Bloemen, W. Brullot, T. T. Luong, N. Geukens, A. Gils, et al., Improved functionalization of oleic acid-coated iron oxide nanoparticles for medical application. J. Nanopart Res, 2012, 14,1100 .

[41] L. Zhang, R. He, H. C. Gu, Oleic acid coating on the monodisperse magnetite nanoparticles. Appl Surf Sci, 2006, 253, 2611-2617.

[42] M. B. Ahmad, M. J. Haron, F. Namvar, B. Nadi, M. Zaki, A. Rahman and J. Amin, Synthesis, Surface Modification and Characterisation of Biocompatible Magnetic Iron Oxide Nanoparticles for Biomedical Applications. Molecules, 2013, 18 (7), 7533-7548.

[43] S. Y. Zhao, D. K. Lee, C. W. Kim, H. G. Cha, Y. H. Kim, Y. S. Kang, Synthesis of magnetic nanoparticles of $\mathrm{Fe}_{3} \mathrm{O}_{4}$ and $\mathrm{CoFe}_{2} \mathrm{O}_{4}$ and their surface modification by surfactant adsorption. Bull. Korean Chem. Soc., 2006, 27, 237-242.

[44] X. Y. Ying, Y. Z. Du, L. H. Hong, H. Yuan, F. Q. Hu, Magnetic lipid nanoparticles loading doxorubicin for intracellular delivery: Preparation and characteristics. J Magn Magn Mater, 2011, 323, 1088-1093.

[45] M. E. Villamin and Y. Kitamoto., Synthesis of multifunctional clustered nano- $\mathrm{Fe}_{3} \mathrm{O}_{4}$ chitosan nanocomposite for biomedical applications, AIP Conference Proceedings, 2018, 1929, 020014.

[46] T. J. Daou, G. Pourroy, S. Begin-Colin, J. M. Greneche, C. Ulhaq-Bouillet, et al. Hydrothermal synthesis of monodisperse magnetite nanoparticles. Chem Mater, 2006, 18, 4399-4404. 